\title{
PERSPECTIVAS INSTITUCIONAIS DOS PROCESSOS AVALIATIVOS DA EDUCAÇÃO SUPERIOR
}

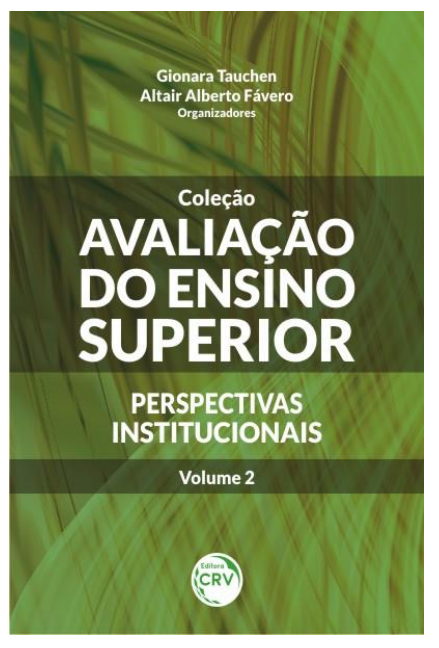

TAUCHEN, Gionara; FÁVERO, Altair Alberto (Org.).

Avaliação do ensino superior: perspectivas institucionais. Curitiba: CRV, v. 2, 2017. 206 p. ISBN 978-85-444-1723-2. doi: 10.24824/978854441723.2 ${ }^{1}$

Evandro Consaltér ${ }^{i}$

${ }^{1}$ Submetido em: 17/09/2017 - Aceito em: 19/09/2017 - Publicado em: 09/11/2017 
Pom a crescente expansão do ensino superior, o controle e eficácia dos mecanismos de avaliação tem ocupado cada vez mais espaço nos principais debates sobre educação na atualidade. Essa discussão é comumente perpassada pelo tensionamento entre autonomia e dependência, qualidade e quantidade, democratização e massificação, por exemplo, tangenciando a diferentes compreensões do estado, das instituições e dos sujeitos educativos acerca desse importante processo.

Assim como são variadas as compreensões acerca dos processos avaliativos, da mesma forma o são os sistemas adotados pelas instituições de ensino superior com a finalidade de desenvolver essa prática. É justamente essa temática que ganha destaque na obra Avaliação do Ensino Superior: perspectivas institucionais, segundo volume da coletânea organizada pelos professores Gionara Tauchen e Altair Alberto Fávero, que se detém sobre as perspectivas institucionais acerca dos processos avaliativos na educação superior. A obra, composta por 10 capítulos, conta com textos de autores do Brasil, Argentina, Angola e Reino Unido e constitui produção parcial dos pesquisadores ligados ao Grupo de Trabalho do Conselho Latino Americano de Ciências Sociais - CLACSO (20162019) Universidades e Políticas de Educação Superior, ao Programa PróMobilidade Internacional (CAPES/AULP) e à Rede de Estudos e Pesquisas em Educação (REPES).
A coletânea tem como primeiro capítulo o texto de autoria dos professores Júlio Bertolin e Glades Felix, intitulado "Avaliação da qualidade da modalidade $\mathrm{EaD}$ na educação superior brasileira: implicações do capital cultural e do background dos estudantes". O estudo faz uma abordagem sobre a necessidade de se considerar o contexto socioeconômico dos alunos nas avaliações de desempenho e qualidade da modalidade $\mathrm{EaD}$ para garantir a eficácia dessas avaliações. A investigação desenvolve-se, sobretudo, a partir do conceito de capital cultural de Pierre Bourdieu e de dois estudos sobre a eficácia escolar, um deles encomendado pelos Estados Unidos, com o nome de Coleman Study, e o outro na Inglaterra com o nome The Plowden Report. A partir dos dados explorados no texto, os autores defendem um rigoroso acompanhamento do desempenho dos estudantes de cursos de $\mathrm{EaD}$ no Brasil através de confiáveis métodos de avalição. Assim, entendem que se poderá melhorar a oferta desses cursos e desmistificar muitas concepções acerca dos mesmos.

A discussão sobre a dinâmica autonomiaavaliação no âmbito jurídico-formal do ensino superior de Angola e seus impactos sobre a agenda avaliativa decretada é objeto de análise do texto de autoria de Tuca Manuel e Maria da Conceição Barbosa Mendes, intitulado "A autonomia para uma avaliação construtivista: o caso do ensino superior da Angola", o qual compreende o segundo capítulo da coletânea. Através de uma abordagem

\begin{tabular}{l|c|c|c|c|c|c|} 
(C) Rev. Educ. Perspec. & Viçosa, $M G$ & v.8 & n.3 & p.518-523 & set./dez. 2017 & eISSN 2178-8359 \\
\hline
\end{tabular}


hermenêutica apoiada em dados documentais, os autores discutem a influência das autonomias para a efetivação de uma avaliação construtivista, que resulte em uma compreensão deste processo de forma mais autônoma e menos normativista. Para os autores, os processos avaliativos institucionais devem balizar-se não apenas pelos documentos que os regem, configurando-se exclusivamente uma ação formal, mas também compreender e envolver os contextos identitários que compõem a instituição.

O terceiro capítulo da obra é intitulado "Avaliação Institucional na Universidade Katyavala Bwila: práticas, finalidades e desafios" e tem autoria de Maria da Conceição Barbosa Mendes, Alberto Domingos Jacinto Quintebo e Divaldo Pereira Carvalho. Com uma abordagem centrada na certificação dos processos operacionais avaliativos da instituição, os autores procuram descortinar os contornos e significados dessa prática aos professores e demais agentes educativos. Por fim, fazem seus apontamentos acerca dos principais desafios colocados no âmbito da avaliação institucional da Universidade de Katyavala Bwila.

Com autoria dos professores Altair Alberto Fávero e Carina Tonieto, o quarto capítulo da coletânea tem como título "Autoavaliação: da cultura do tédio à promoção da cultura do sentido nas instituições de ensino". Os autores propõem uma discussão sobre como promover uma cultura do sentido a partir dos processos autoavaliativos. Para isso, partem de uma série de questionamentos acerca do sentido do termo "cultura", visto a polissemia de conceitos que o circundam. Para dar conta da devida reflexão, os autores buscaram amparo bibliográfico, sobretudo, nos estudos de La Taille (2009), Bauman (1998) e Savater (2002). Ao final, sinalizam que são infinitas as possibilidades de angariar elementos promotores de uma formação da cultura de autoavaliação institucional. Todavia, o desafio dos gestores é colocalos em prática para que a educação superior seja um processo de sentido à vida, propositivo e contextualizado, e não ao contrário, como um processo meramente formal, de "imbecilização", inclusive das instituições que o promovem.

O quinto capítulo da obra tem como título "O Pensamento Crítico e a Avaliação na Formação de Professores" e é de autoria de Arlinda Conceição dos Santos. O objetivo do texto desdobra-se sobre a importância do pensamento crítico para o desenvolvimento das capacidades argumentativas dos estudantes. Além disso, também perpassa pelo estudo uma abordagem sobre a importância do professor construir uma postura científica frente ao exercício da docência para, assim, contribuir com a profissionalização e o reconhecimento de sua atividade. Para tal, a autora aponta algumas propostas de atividades as quais considera necessárias à execução do pensamento crítico nas aulas de ensino superior. Entre essas atividades, destaca a produção de materiais que possam ser utilizados por docentes nas aulas; a definição de linhas orientadoras e

\begin{tabular}{l|l|l|l|l|l|l} 
(C) Rev. Educ. Perspec. & Viçosa, $M G$ & v.8 & n.3 & p.518-523 & set./dez. 2017 & eISSN 2178-8359 \\
\hline
\end{tabular}


a concepção de instrumentos de trabalho que suportem práticas pedagógicas com destaque no pensamento crítico; e o desenvolvimento de modelos e estratégias úteis para os docentes e estudantes. Essas atividades, conforme a autora, quando tomadas de forma integradora à disciplina, podem diminuir as dificuldades e deficiências dos processos de ensino e aprendizagem.

Com o título "Evaluación y Aprendizaje", o sexto capítulo da coletânea tem como autor o professor Charly Ryan, da Universidade de Winchester/Inglaterra. Em seu estudo, Ryan apresenta uma cartografia sobre o desenvolvimento das avaliações dos estudantes de uma universidade do sul da Inglaterra. Além disso, também tece uma análise acerca das vantagens de orientar-se através de uma avaliação pautada nos sistemas da instituição e da avalição com foco central nos estudantes. Essa metodologia, segundo o autor, contribui para o fornecimento de subsídios com vistas ao desenvolvimento e ao aprimoramento curricular. A partir de seus estudos, Ryan entende que cultivar processos de avaliação democráticos faz com que se crie uma cultura de avaliação capaz de mudar de forma propositiva as relações no ambiente educacional, gerando impactos qualitativos e quantitativos a todos os envolvidos no processo formativo.

Por sua vez, o sétimo capítulo da obra tem como autores os professores Pedro Cardoso da Silva e Vivian Puebla Ramírez, ambos do Instituto Superior de
Ciências de Educação do Cuanza-Sul da Universidade de Katyavala Bwila, de Angola. Intitulado "A Avaliação da Aprendizagem na Formação Inicial de Ensino Superior Pedagógico", o trabalho tem como objetivo destacar a importância da avaliação ocupar espaço como uma preocupação na formação pedagógica de modo a reforçar o seu impacto social e profissional. Além disso, o estudo também faz uma análise, em um recorte temporal a partir de 2001, de diferentes modelos avaliativos existentes em Angola, apontando suas potencialidades e fragilidades, bem como discutindo as funções, modalidades, técnicas e os instrumentos de avaliação correspondentes às suas especificidades.

Com o título "Avaliação Integral das Aprendizagens no Ensino Superior à Luz dos Documentos que a Regulam: um estudo de caso dos ISCED da Universidade Katyavala Bwila-Angola”, o oitavo capítulo da obra é de autoria dos professores angolanos Alberto Domingos Jacinto Quintebo e António Tiago Sapalo. Os autores apresentam os resultados de um estudo realizado em instituições de ensino superior de Angola, no âmbito da formação de professores, confrontando as práticas avaliativas das aprendizagens realizadas nessas instituições e os documentos que as regulam. A partir do estudo, os autores constaram que as avaliações das aprendizagens devem ser um processo que permita proceder a leitura das mudanças que se operam nos estudantes ao longo do processo formativo esperado no ensino superior. A partir 
desses levantamentos, deve ser possível a promoção contínua da melhoria dessas práticas e procedimentos de avaliação das aprendizagens à luz dos documentos institucionais que as regulam, com vistas ao aprimoramento curricular e a qualificação do ensino.

O nono capítulo do livro é de autoria do professor da Universidade Federal da Fronteira Sul, Jerônimo Sartori, e recebe o título de "Avaliação da Formação Continuada de Coordenadores Pedagógicos: modalidade projetos de extensão". Em seu estudo, Sartori realiza uma análise acerca de um projeto de formação continuada de coordenadores pedagógicos em projetos de extensão desenvolvidos através de sua universidade. $\mathrm{O}$ autor considera que $\mathrm{o}$ ato de avaliar tem relação direta com o saber e o fazer do coordenador pedagógico, o que exige atualização permanente como forma de qualificar esses processos e, assim, retroalimentar a prática do coordenador a partir dos seus limites e das possibilidades identificadas. Ao final de seu estudo, Sartori destaca a necessidade de o coordenador pedagógico colocar permanentemente em seu horizonte a temática da avaliação, considerando os desafios, conflitos e contradições que a ela se colocam a fim de dinamizar reflexivamente esta prática e a sua importância no âmbito pedagógico. en Carreras a Distancia”. Os autores analisam o processo de afiliação dos estudantes universitários em cursos que usam ambientes virtuais de aprendizagem como parte do processo de avaliação de sua trajetória no primeiro ano da vida universitária. $\mathrm{O}$ estudo tem como campo de investigação a Universidade Nacional de Lanús, na Argentina. Os autores apontam que essa modalidade de ensino requer dos estudantes uma capacidade de autogestão desde o início da trajetória acadêmica. Além disso, também apontam alguns falsos conceitos que se criaram acerca da modalidade de ensino à distância, como, por exemplo, que exige menos tempo de dedicação por não ser necessário o deslocamento até a universidade. Assim, consideram essencial a participação da instituição na orientação dos acadêmicos em relação a uma organização temporal e espacial adequada visando uma exitosa trajetória no curso.

Ao final da leitura da obra Avaliação do Ensino Superior: perspectivas institucionais é possível afirmar que o conjunto de textos que a compõem consiste em um rico material, que proporciona o diálogo e a construção

Por fim, o décimo capítulo da coletânea é de autoria de Esteban Pintos Andrade, Patrícia Chechele e Vanesa Luro, tendo como título "La Afiliación del Estudiante 
de possibilidades a partir da interação com as diferentes realidades abordadas pelos autores. Ampliar o conhecimento acerca das possibilidades e desafios pontuados pelos processos de avaliações institucionais é um caminho a ser perseguido por docentes, gestores e instituições que buscam a qualificação do ensino e de suas estruturas didáticas e curriculares.

Diante das novas demandas da sociedade moderna que recaem sobre as instituições de ensino superior, a coletânea resenhada firma-se como um importante parâmetro capaz de colocar luz sobre a essência de um processo que deve, ao mesmo tempo, validar, considerar e compreender tanto aspectos quantitativos como qualitativos. Para isso, as experiências relatadas nesta obra, provenientes de diferentes contextos e países, servem de arcabouço para a construção de sólidos pilares orientadores de eficazes práticas de avaliação institucional. Assim, consequentemente, permitem a projeção de ações que possam qualificar a oferta do ensino de nível superior. Por fim, consideramos uma obra de leitura obrigatória para gestores e docentes envolvidos com o âmbito da avaliação em suas instituições.

\section{Sobre o Resenhista}

\footnotetext{
'Evandro Consaltér: Doutorando em Educação (Bolsista Capes) pela Universidade de Passo Fundo (UPF). Membro do Grupo de Pesquisa Docência Universitária, Políticas Educacionais e Expansão da Educação Superior, vinculado ao Programa de Pós-Graduação em Educação da Universidade de Passo Fundo - RS/Brasil. E-mail: evandroconsalter@gmail.com
} 